RESEÑAS E INFORMACION BIBLIOGRAFICA 

BRIGITTE SCHLIEBEN - LANGE, Pragmática Linguística, Madrid: Editorial Gredos, 1987, pp. 190.

En 1975 se publicó en Stuttgart Linguistische Pragmatik, estudio que en versión española de Elena Bombin ha sido incluido recientemente por la Editorial Gredos en su colección de manuales (no 66).

La obra pretende introducirnos en una disciplina que ha abierto un gran campo de posibilidades y nuevas expectativas en el panorama de las investigaciones sobre el lenguaje, la pragmalinguística o pragmática linguistica.

Como toda teoría que aspire al rigor científico, la pragmática se impone la tarea prioritaria de delimitar su objeto de estudio y adoptal ciertos presupuestos metodológicos que garanticen una explicación coherente y exhaustiva del mismo. El libro de Schlieben-Lange es, sin duda, una extraordinaria contribución a este propósito.

Sus contenido se organiza en cuatro capitulos más una introducción general donde se critican las insuficiencias de tres definiciones frecuentes de "pragmática": "doctrina del empleo de los signos", "linguística del diálogo" y "teoría de la acción de habla" (p. 12).

Son concepciones distintas sobre el alcance de esta recién estrenada perspectiva, forjadas en un proceso de confluencia de muy variadas tradiciones que, sin embargo, tienen en común el interés por las formas de comunicación intersubjetiva. De ahí que en el capítulo primero de la obra se trace una historia de la pragnática que pasa por puntos de referencia muy concretos. Entre ellos habría que distinguir unos antecedentes intralinguísticos, concretamente la evolución de la gramática transformacional, y otros extralinguisticos en el sentido de que remiten a la filosofía y las ciencias sociales.

Centrándose en sus figuras más representativas, SchliebenLange hace una sintesis de las corrientes filosóficas que desarrollan principios pragmáticos: Pragmatismo americano (Ch.S. Peirce, Ch. Morris), empirismo lógico (L. Wittgenstein, R. Carnap), y filosofía del lenguaje ordinario (J.L. Austin, J.R. Searle, H.P. Grice). A ellas añade otras dos direcciones de fuerte implantación en Alemania: De una parte, la filosofía trascendental y dialéctica, representada por la hermenéutica de K.0. Apel y J. Habermas, y de otra, la aplicación de conceptos y categorias del marxismo a una teoría de la acción de habla (G. Klaus, A. Leontiev, U. Maas y W. Kummer).

En cuanto a la sociología, se hace referencia al Interaccionismo Simbólico y la Etnometodología, tendencias que alcanzaron sus 
mayores logros en Norteamérica y muy próximas a una sociolinguistica donde las manifestaciones de habla se vinculan a las situaciones de comunicación a través de los modelos funcionales de $K$. Buhler y $R$. Jakobson.

El filtimo apartado de] amplio capítulo primero está dedicado a los planteamientos pragmáticos intralingüisticos de los que hablábamos más arriba: "E1 'descubrimiento' de la pragmática, que tuvo como consecuencia la ampliación observable hoy del concepto de la lingüistica misma, tuvo lugar en el marco de la gramática transformativa" (p. 75)

A pesar de la reivindicación de una "Iingiística del habla" por parte del estructuralismo europeo postsaussureano, la mayoría de sus trabajos avanzaron por el camino de lo homogéneo, de la lengua. En este sentido, el transformacionalismo se mostró más receptivo hacia algunas de las tradiciones antes mencionadas, sobre todo cuando surgió la polémica en torno al modelo de Chomsky, predominantemente sintáctico

Con la irrupción de posturas semanticistas entran en juego aspectos de la semántica lógica, por ejemplo en la explicación de las 1 lamadas "expresiones indice" (p. 77), y de la filosofía del lenguaje, como 10 reflejan las numerosas hipótesis sobre la estructura de los actos ilocutivos, la inclusión de las presuposiciones en la descripción de entnciados, así como de los postulados conversacionales de Grice, que "pueden ser invocados para explicar la diferencia entre lo dicho realmente (en la superficie) y 10 pensado (en la estructura profunda)" (p. 80$)$.

El capitulo segundo, titulado "Esbozo de una pragmática linguistica", es la parte esencial de la obra y está dividido en tres partes:

1.- Observaciones preliminares

2. - E1 marco universal de una pragmática 1 inguística

3. - Las tareas empiricas de una pragmática lingüistica

En ellas la autora nos ofrece sus puntos de vista particulares sobre las lineas maestras que deberian orientar la investigación pragmática dentro de una teoria linguística que abarque fenómenos no clasificados ni descritos por la sintaxis o la semántica. Cuando se constata la relevancia del "usuario del signo", surge la necesidad de revisar las dicotomías lengua/ habla y competencia/ actuación, en el sentido de que "parole" y "performance" no pueden limitarse a la mera actualización de unas reglas ideales o de sistemas de signos dados "a priori". Más bien habría que considerar al hablante tanto en su faceta de creador de signos como en la de sujeto de acciones 1 inguisticas en ciertos contextos y situaciones y con unas determinadas intenciones y 
creencias.

Partiendo de esta base se perfila el marco de una pragmática linguistica universal como teoría de la "competencia comunicativa" --concepto tomado de J. Habermas-- que tendria por objeto los universales del habla, frente a aquéllas que se han venido ocupando sólo de los universales del sistema.

Ya en el terreno de 10 empírico, y salvando las dificultades que entraña la distinción universal/ particular, Schlieben-Lange pasa revista a los temas capitales objeto de reflexión y controversia entre los pragmatistas: Clasificaciones de actos ilocutivos y expresiones linguísticas que los manifiestan (verbos actuativos, indicadores ilocutivos, particulas modales...), condiciones exigidas por la perlocución, actos de habla indirectos y su conexión con los postulados conversacionales, presupuestos y universos de discurso, etc.

Especial atención merecen las secuencias o encadenamientos de acciones de habla, bien como series "reguladas convencionalmente" ( $\mathrm{p}$. 128) (preguntar/ responder, hacer un reproche/ justificarse, saludar/ devolver el saludo...), o bien como ámbito de estrategias discursivas muy frecuentes en el transcurrir de la comunicación diaria.

El capitulo tercero es una breve reflexion sobre la influencia que los planteamientos pragmáticos han ejercido sobre disciplinas linguisticas colindantes. Subyace a esta cuestión la alternativa de considerar que la pragmática ha adquirido o puede adquirir el status de ciencia autónoma, o bien que no existe como tal, sino que asistimos a un proceso de "pragmatización" de la linguística en todos los órdenes con un giro radical en cuanto a métodos y objetivos de investigación. Claros ejemplos de este "cambio de paradigma" se dan en la semántica, lingüistica del texto y sociolingüistica.

En el primer caso, el interés parece desplazarse desde la semántica estructural y la semántica extensional hacia las innovaciones introducidas por la "semántica práctica" (p. 152) y la "semántica de la instrucción" (p. 153). Por otra parte, lingiistica del texto y pragmática presentan en su evolución etapas paralelas una ve traspasado el límite de la frase y situado su punto de mira en "el juego de la acción comunicativa" como "categoria fundamental de ambas ramas cientificas" (p. 155). En cuanto a la sociolingiistica, Schlieben-Lange considera que los resultados hasta ahora conseguidos podrían superarse atendiendo al hecho de que "las diferencias decisivas entre hablantes de distintas capas residen en el plano pragmático" (p. 159).

Echamos de menos en esta sección un comentario especifico subre Las relaciones entre sintaxis y pragmática. En mi opinion, todo intento de incluir sistemáticamente componentes pragmáticos en una teoría sintáctica debería seguir las directrices marcadas por la Gramatica Funcional de S. Dik, 
En el cuarto y último capitulo, "La comunicación, objetivo didáctico", se trata la necesidad de incluir en el dominio de la enseñanza de las lenguas no sólo componentes teóricos normativos y descriptivos, sino también los mecanismos prácticos que rigen las acciones lingüisticas.

Completan la obra una amplia bibliografía que pone de manifiesto la pujanza de una auténtica "escuela" alemana de pragmatistas, cuya figura fundacional sería D. Wunderlich, más dos índices sumamente útiles, uno de conceptos y otro de autores.

Durante los doce años transcurridos entre la publicación de Linguistische Pragmatik y su difusión en España, los estudios sobre el lenguaje como fenómeno comunicativo, intersubjetivo y social han conocido un desarrollo inusitado, tanto en el plano de la pragmática general como en el de la pragmática aplicada a problemas concretos en determinadas lenguas. Sin embargo, si en 1975 Schlieben-Lange advertia en las primeras páginas de su trabajo que "la esfera del objeto de la pragmática linguística hasta ahora no está en manera alguna claramente definida" ( $\mathrm{p}$. 11), la situación actual no ha variado sustancialmente. Sigue siendo "una disciplina de perfiles aún borrosos", como afirma E. Bustos en el prefacio de su Pragmática del Español (UNED, Madrid, 1986).

Esperemos que las pautas de investigación sugeridas a 1o largo del libro que reseñamos sirvan de estímulo para afianzar esta parcela, poco explorada aún, en el marco de la linguística española.

Carmen Lanero

Universidad de León

JUAN LUIS ONIEVA MORALES, Fundamentos de gramática estructural del español, Madrid: Editorial playor, 1986, pp. 319.

Nos sorprende, de nuevo, gratamente el profesor Onieva Morales con otra obra, publicada por la editorial Plavor. Se trata en este caso de Fundamentos de gramática estructural del español, obra donde, con rigor y coherencia, expone los rudimentos básicos de una gramática estructural del español.

Al igual que en ocasiones anteriores (Diccionario básico de terminologia gramatical (1986) y posteriores, Cómo dominar el análisis gramalical básico (1987) y Cómo dominar el análisis gramatical superior (1987)), la orientación es eminentemente práctica, fruto de la trayectoria pedagógica, en distintos niveles, del autor. 
Como queda insinuado en el título (Fundamentos ...), parece que no se pretende un estudio exhaustivo, labor prácticamente imposible por el gran numero de temas que trata, sino, más bien, constituye un instrumento de trabajo, auxiliar para profesores y básico para alumnos de enseñanzas medias.

Fundamentos ... se estructura en cuatro partes bien diferenciadas que se corresponden, si exceptuamos la primera, dedicada a señalar los postulados básicos de la gramática estructural, con las partes en que tradicionalmente se ha venido estudiando la gramática: nivel fónico (fonético y fonológico), nivel morfosintáctico (morfología y sintaxis), nivel léxico-semántico. Cada parte se divide en una serie, más o menos amplia, de capitulos, subdivididos en dos partes, una donde se esbozan los contenidos teóricos del tema y otra, de carácter práctico, donde el profesor Onieva Morales formula tres tipos de ejercicios: 1.- Cuestionario donde se plantean preguntas teóricas sobre los contenidos expuestos en el tema; 2.- Ejercicios propiamente dichos; 3.- Autoexamen donde se debe elegir, entre cuatro, la respuesta correcta. Este planteamiento se repite a lo largo de toda 1a obra de donde se desprende una impresión de sistematicidad y orden, apropiado a su carácter fundamentalmente didáctico.

En la primera parte, expone el autor, en tres capítulos, los conceptos metodológicos de una gramática estructural (noción de sistema o estructura, el signo linguistico y sus caracteristicas, dicotomías saussureanas, doble articulación del lenguaje, ...) y los criterios utilizados en la descripción del hecho linguístico (formal, funcional o sintáctico, y semántico). A modo de sintesis, contrasta -no olvidemos la dimensión pedagógica-- los principios de la gramática estructural con los de Ia tradicional.

El profesor Onieva Morales hace, en la parte siguiente, un breve recorrido a través de las nociones fundamentales de la fonética y fonologia generales: fonema, sonido, rasgo pertinente, oposición fonológica, así como la descripción de los órganos articulatorios, con 10 que clasifica los fonemas del español y quedan configurados los subsistemas vocálicos y consonánticos del español. Junto a esto, son vistos también los diptongos y triptongos, la silaba como el "grupo fonético más elemental" ( $p$. 71) y los rasgos suprasegmentales del español: acento y entonación.

La parte más densa del libro es la tercera, en la que el autor, a lo largo de diecisiete capitulos, trata los aspectos morfológicos y sintácticos del español. Concibe la gramática como la disciplina que "estudia el sistema de la lengua concediendo prioridad a la forma linguística como soporte de la significación y desembocando en el estudio de la función de cada unidad" ( $p$. 87). El enunciado es la unidad básica de segmentación que responde a dós estructuras sintagmáticas diferentes: oración y frase; el rasgo pertinente que diferencia estos dos tipos de enunciados es la presencia de dos elementos básicos constitutivos en la oración (sujeto y predicado) y 
su ausencia en la frase. Fiel a la tradición gramatical sitúa la oración en el nivel inferior del análisis y la define como la "unidad de comunicación (o de habla) que posee independencia sintáctica, marcada con una curva de entonación y con sentido completo mas actitud del habalante" (p. 94). A través de la combinación de criterios, es decir, 1a. caracterización sucesiva de su valor funcional, formal y semántico, define las tradicionalmente 1 lamadas "partes de la oración" - categorías gramaticales: sustantivo, adjetivo, verbo, adverbio, pronombre, artículo, preposición y conjunción.

En el llamado nivel paradigmático, una vez definido el sintagma. como "el grupo de elementos linguísticos que forman una unidad (y desempeñan una función) en una organización jerarquizada" (p. 129), se analiza la estructura de: 1.- el sintagma nominal, que, en general, suele presentar la estructura de Determinantes-Núcleo-Adyacentes. El núcleo es siempre un sustantivo o un elemento sustantivado. Los determinantes actualizadores (articulo, demostrativos y posesivos) y cuantificadores (numerales e indefinidos) son "elementos de naturaleza morfemática que actualizan al sustantivo, 10 sitúan en relación con las personas gramaticales o precisan cuantitativamente la extensión de su contenido" (p. 143). Los adyacentes (adjetivo, complemento preposicional y aposición) se refieren "al sustantivo añadiéndole caracterizaciones semánticas concretas" (p. 143). 2,- el sintagma verbal, es decir, el verbo como núcleo del predicado y sus desinencias o morfemas de modo, tiempo, aspecto, persond, y número. Mantiene la distinción formal entre voz activa y voz pasiva. Completan este capitulo, una clasificación de los verbos atendiendo a su empleo gramatical y al modo de acción, unas breves reflexiones sobre las formas no personales del verbo y el análisis de las llamadas perifrasis verbales.

Da comienzo a la sintagmática con el estudio de los complementos del verbo, donde se analizan las estructuras sintagmáticas y las reglas de identificación de las funciones oracionales que concretan el significado del verbo: complemento directo, complemento indirecto, suplemento, complemento agente, atributo, y complemento predicativo. La presencia o ausencia de los anteriores complementos del núcleo del predicado permite distinguir cuatro esquemas oracionales básicos: estructura atributiva, estructura transitiva, estructura de suplemento, $\quad \mathrm{v}$ estructura intransitiva. Prescinde del binarismo tradicional que enfrentaba "oraciones atributivas" y "oraciones predicativas". Todas tienen predicado, en un caso es nominal (o. atributivas) y en otro es verbal (o. predicativas), y todas predican algo: "el predicado puede atribuir una cualidad al sujeto (el árbol es alto) o puede expresar una acción del mismo (el ciclista corría mucho)" (p. 193). En este mismo capítulo trata las estructuras transitivas pasivas y las oraciones con "se" de indeterminación de agente, como transformaciones en la estructura del predicado. Respecto al primer punto, como ya vimos, defiende, siguiendo la tradición gramatical, la existencia formal de dos voces en español, en contra de algunos autores estructuralistas que aceptan el contenido de pasividad 
en las tradicionalmente 1 lamadas "oraciones pasivas", pero niegan que nuestra gramática deba registrar esa clase de oraciones puesto que se identifican con las atributivas con ser. En cuanto al signo morfológico, átono, no autónomo/se/, discrepamos con el autor en algunos puntos del tratamiento de este elemento: 1. - No nos parece, en absoluto, acertado caracterizar a las oraciones con/se/ impersonal, entre otras cosas, por llevar un verbo de naturaleza intransitiva: se observó a los enfermos - - (impl. se LOS obervó), se observó a 1as enfermas --> (impl. Se LAS observó); 2.- En la oración se vende ropa usada, en la que el autor admite las dos posibilidades: impersonal refleja y pasiva refleja, nos inclinamos a considerarla de pasiva refleja (Se venden ropas usadas); 3. - No existe diferencia gramatical entre reflexivo y recíproco: "El hecho de que un sujeto plural se refiera a dos o más entes de la realidad entre los cuales se establece una actividad mutua, es cuestión de pura sustancia que no se refleja en la forma del contenido" (Vid.: Alarcos Llorach, Estudios de Gramática funcional del español, 1980, p. 215).

Partiendo del binomio opositivo oración/proposición, tan explotado por los gramáticos en los últimos veinte años, y de la distinción entre oración simple, compuesta y compleja, estudia en los capitulos siguientes la conexión de elementos funcionalmente equivalentes: coordinación, y la conexión de elementos de categoría distinta: subordinación. Clasifica las oraciones coordinadas en función del contenido semántico del conector que las une. Atendiendo al grado de incorporación de la subordinada con respecto a la principal, divide estas oraciones en inordinadas, y subordinadas propiamente dichas. Las primeras son "aquellas que funcionan como un elemento constituyente de la principal (sujeto, complemeto directo, suplemento, etc.) o como modificantes de un elemento de la principal (advacente, complemento del nombre, complemento del adjetivo)" (p. 223). Las subordinadas son "aquéllas que no funcionan como un elemento constituyente de la principal ni como modificantes de un elemento de la principal, sino que modifican a la proposición principal en su conjunto" (p. 224). En el primer grupo se incluyen las tradicionalmente 11 amadas "oraciones subordinadas sustantivas" y "oraciones subordinadas adjetivas" que cumplen todas las funciones que el sustantivo y el adjetivo, respectivamente desempeñan en la oración simple. Las subordinadas propiamente dichas desempeñan el mismo papel que el adverbio en las simples: son las "subordinadas circunstanciales o adverbiales". Atendiendo a un criterio exclusivamente semántico las clasifica en tres grupos: 1.Proposiciones subordinadas circunstanciales propiamente dichas: temporales, locales, y modales; 2.- Proposiciones subordinadas circunstanciales que expresan relación cuantitativa: comparativas; 3. Proposiciones subordinadas circunstanciales que expresan relación causativa: causales, consecutivas, condicionales, y finales.

Los cinco capitulos correspondientes a la última parte en que se estructura el libro se los reparten la lexicología y la semántica. Los préstamos léxicos, la estructura de las palabras (lexema + morfema) los procedimientos de creación de palabras: derivación, composición 
parasintesis, son analizados por la lexicología. Del significado de las palabras, del estudio de la significación múltiple: sinonimia, polisemia y homonimia, y de los posibles cambios que se producen en ellos a través del tiempo se ocupa la semántica. Concluye con un capítulo dedicado a la semántica estructural. Esta disciplina ha sido el fruto del esfuerzo por aplicar los principios estructurales con que se ha operado en otras ramas de la lingúistica. Pretende estudiar el significado que adquieren las palabras como consecuencia de las mutuas relaciones que se establecen en el sistema de la lengua. Surgen asi las nociones de campo semántico, sema, "unidad básica de significación", șemema y archisemema.

Una bibliografía fundamental, que se nos antoja excesivamente somera y escueta, y las soluciones a los autoexámenes planteados en cada capítulo rematan la obra.

En definitiva, 10 realmente destacable, como conclusión global es 10 valioso del trabajo que se nos presenta. Ardua y dificil tarea es la que ha llevado a cabo el profesor Onieva Morales y en la que ha logrado sintetizar, con gran rigor, un panorama coherente, organizado y sumanete pedagógico, tanto en la vertiente teórica como en la práctica, la gramática estructural del español.

EDUARDO BUSTOS, Pragmática del español: negación, cuantificación y modo, Madrid, UNED, 1986, pp. 272.

La lectura de Pragmática del español ... exige adentrarse en el difícil campo de la pragmática con todos los riesgos que ello conlleva para un lector no avezado. Sin embargo, no podemos negar que a la vez resulta apasionante ya que nos permite descubrir hasta qué punto los aspectos "trascendentales" de la comunicación linguística influyen en los intercambios comunicativos. Son esos aspectos de los que se ocupa dicha disciplina. En palabras de Angel Manteca Alonso-Cortés "la pragmática es el estudio de los principios y reglas que rigen los intercambios 1 inguísticos entre hablantes, los actos que con el uso del idioma pueden efectuarse, $y$, en general, de todo el conocimiento común de los hablantes pertinente para la comprensión entre ellos" (Linguística general, Madrid, Cátedra, 1987, p. 180). De esto se deduce la importancia que la pragmática--también llamada pragmalingüistica o lingüistica pragmática--tiene para una comprensión global del fenómeno comunicativo.

La obra de Bustos que ahora comentamos se divide en cuatro capítulos. El primero de ellos incluye reflexiones de carácter general 
mientras que, los otros tres se dedican al análisis de fenómenos pragmáticos concretos del español: 1a referencia, la cuantificación y los modos. Como puede comprobarse, la obra se inscribe dentro del marco de la pragmática aplicada.

Si advertimos una falta de correspondencia --ya señalada por $H$. Haverkate en su comentario a esta misma obra (Journal of Pragmatics, Vol. 11/5, October, 1987, p. 678)-- entre el título del ensayo y su contenido, ya que el segundo capítulo trata sobre la referencia, tema no anunciado en el subtitulo, mientras que a la negación, primer objeto de estudio mencionado, no se le dedica ningún capítulo concreto. Bien es cierto que este último tema es esencial en el tratamiento de los otros que ocupan el libro, pero quizá sí hubiera sido útil un apartado especifico en el que se recogieran todas las observaciones sobre el mismo.

El primer capitulo, como ya hemos dicho, se dedica a cuestiones generales. Se parte de la distinción entre competencia comunicativa y competencia linguística para pasar luego a considerar la problemática de los actos verbales que, en su relación con el particular contexto en el que se inscriben, son el objeto de estudio de la pragmática.

Otio concepto esencial es el de contexto. Bustos examina las propuestas de autores como Lewis ("General Semantics", Synthese, 1970, 22, pp. 18-67), van Dijk (Text and Context, Londres, Longman, 1977) y Gazdar (Pragmatics, Nueva York, Academic Press, 1979) y a partir de ellas elabora su propia definición que da una importancia esencial a las creencias mantenidas por los participantes en el intercambio comunicativo. La adecuación pragmática de un acto de habla es, ante todo, una cuestión de hablante y oyente, porque, en principio, sólo ellos tienen acceso al contexto real en que la comunicación se produce. Sólo emisor y receptor conocen las creencias pertinentes y adecuadas para la emisión de un juicio. Ese conocimiento compartido constituye la base común o universo pragmático del discurso, que no se mantiene invariable a 10 largo del acto comunicativo, sino que está sujeto a un proceso de incrementación. Teniendo en cuenta 10 anterior, Bustos establece que "el contexto de un intercambio linguístico (...) está constituido por las creencias compartidas por hablante $v$ oyente, y por las creencias atribuidas por aquél a éste" (p. 35).

En el análisis del funcionamiento pragmático de la negación se parte de lo establecido por Givon ("Negation in Language: Pragmatics, Function, Ontology", Syntax and Semantics, 9:Pragmatics, Nueva York, Academic Press, 1978, pp. 69-112), cuando considera que, desde el punto de vista presuposicional, los actos de habla negativos están más marcados que los correspondientes afirmativos. De acuerdo con la máxima de relevancia según la cual el hablante no debe afirmar ninguna oración que forme parte del contexto, la aserción de p "presupondrá" que en el mismo no está p, mientras que su negación "presupondrá" que en el contexto se halla p. Es decir, la afirmación introduce un elemento nuevo, a diferencia de lo que ocurre con la negación que lo 
elimina.

Los intercambios comunicativos se rigen por el principio de coherencia discursiva que tiende a conservar y aumentar --si es posible-- la consistencia de los contextos. Bustos sostiene que la conducta linguística orientada a aumentar la consistencia contextual se llama constructiva. Es 10 que hacen, en general, los actos de habla afirmativos. Por el contrario, "un acto de habla negativo se producira la mavor parte de las veces para eliminar un determinado elemento del contexto, un elemento que es inconsistente con las creencias del hablante" (p. 53).

Tras un análisis de las construcciones anafóricas, se concluye afirmando la necesidad de tener en cuenta la teoría pragmática para una correcta comprensión de los fenómenos del lenguaje.

El segundo capitulo estudia el problema de la referencia. El autor, considerando que todo $\mathrm{SN}$ empleado referencialmente en una oración conlleva la presuposición de que existe un referente al que el sintagma nominal designa, analiza el comportamiento pragmático de los sintagmas nominales definidos, indefinidos, los nombres propios, las expresiones anafóricas y las oraciones de relativo restrictivas y no restrictivas.Sin embargo, no en todos estos casos se puede hablar de presuposición ya que, por ejemplo, al tratar las propiedades referenciales de los SN indefinidos no está del todo claro si es una relación de implicación o de presuposición la que da cuenta de dichas propiedades. Otro tema conflictivo se presenta cuando la oración con un SN definido o indefinido tiene una negación que es interpretada en sentido externo. Cuando esto ocurre dicha oración carece de presuposiciones referenciales.

Para dar una solución sistemática a todo 10 anterior, Bustos propone que "se trata de implicaciones. Una oración afirmativa implica la afirmación de que existe lo referido por su(s) SN, mientras que 1 correspondiente oración negativa sólo tiene esa implicación cuando es interpretada, por el hablante y el oyente, en un sentido interno" ( $p$. 88). Existe, sin embargo, un problema que radica en saber cuándo un hablante y un ovente interpretan una determinada oración negativa en su sentido externo o interno. No obstante, dicha ambigüedad desaparece al considerar la emisión de tales oraciones en un contexto determinado.

En la segunda parte del capitulo se discute el carácter presuposicional de algunas de las tradicionalmente 11 amadas oraciones subordinadas. Se hace especial referencia a la relación existente entre los verbos factivos y la negación. La tesis presuposicionalista ortodoxa sostiene que dichos verbos "presuponen la verdad de sus complementos, tanto en oraciones positivas como negativas" ( .95 ). Sin embargo, no es difícil encontrar contextos en los que oraciones negativas con verbos factivos carecen de tal presuposición, e incluso, ésta puede ser negada mediante cláusulas cancelatorias, como Bustos 
demuestra a través de una serie de ejemplos. Es lo que ocurre en el. caso de Juan no descubrió que Marta le fuera infiel, en realidad ésta no le es infiel (p. 95). Dado que uno de los caracteres de la presiposición es su no cancelabilidad, el autor afirma que la conexión entre estas oraciones negativas con predicados factivos y sus presuposiciones se describe de modo correcto como una relación de implicatura conversacional. En resumen, las oraciones factivas afirmativas tienen un comportamiento presuposicional distinto del que tienen las negativas. Ello se debe a las peculiares propiedades pragmáticas que poseen las ultimas.

Bustos concluye afirmando que, aunque la función pragmática general de las oraciones negativas es la establecida por Givon en el artículo antes citado, las oraciones factivas negativas también "pueden utilizarse para efectuar afirmaciones complejas que, a través de las relaciones de inferencia, introducen varios elementos al tiempo en el contexto que manejan el hablante y el oyente" (p. 128). Es decir, mediante la proferencia de una oración negativa, el hablante puede desear introducir en el contexto tanto esa oración como su implicatura conversacional. Esta no ha de ser un elemento contextual ya que si lo fuera no aportaria nueva información.

La cuantificación es el tema del siguiente capitulo y en él Bustos desarrolla más extensamente 10 que ya habia tratado en su artículo "La dimensión pragmática de las expresiones cuantificacionales clásicas del castellano", Contextos, II/4, 1984, pp. $73-86$.

En primer lugar, se definen los conceptos de implicación convencional, implicación lógica e implicatura conversacional. Estos dos últimos se diferencian por la fuerza del vinculo que establece el seguimiento de las convenciones en que se basan. En el caso de la primera, tal vinculación alcanza su máximo grado de modo que un hablante no puede desligarse de 10 lógicamente implicado por sus afirmaciones. En la implicatura conversacional esa vinculación es más débil. Depende tanto del contexto compartido por hablante y oyente que un observador ajeno al mismo dificilmente puede captar la implicatura. Esta es el resultado de un acuerdo convencional cuyo ámbito o alcance puede limitarse a una pequeña comunidad lingiística, incluso sólo a la constituida por hablante y oyente.

Entre estos dos tipos de relaciones se sitúan las implicaciones convencionales. Estas se caracterizan por no ser cancelables, es decir, el hablante no puede considerarse no responsable de lo que ha implicado convercionalmente. Son desmontables o prescindibles, 10 que significa que el enunciado portador de la insinuación puede sustituirse por otro sinónimo que no comporta dicha implicacion.

Este tipo de implicaciones puede tener una doble funcion pragatica dependiendo de que figuren o no en el contexto de la proferencia. En el primer caso no introducirian nueva información, sino que evoca- 
rían la ya existente, mientras que, de ocurrir lo segundo, sí incrementarían la base contextual.

La parte central del capítulo se dedica a aspectos convencionales y conversacionales de la cuantificación. El objetivo que el autor se propone no es establecer una nueva teoría lógica sobre el tema, sino "allanar el camino para aquéllos que deseen construir o utilizar un lenguaje formal más rico del habitual para formular sus teorías semánticas y/o pragmáticas sobre nuestra lengua" (p. 150).

Bustos analiza los cuantificadores clásicos (todos y expresiones afines, cada, cualquiera, ...), la cuantificación de pluralidad (mucho(s), poco(s), la mayoría y sus variantes...), y, por último, los cuantificadores presuposicionales (sólo, incluso, ni siquiera...).

E1 examen de la relación existente entre negación y cuantificación pone punto final a este apartado.

El último capítulo de la obra tiene dos secciones. En la primera, se analizan las consecuencias pragmáticas derivadas del empleo de indicativo y/o subjuntivo en las oraciones subordinadas en las que es posible dicha alternancia. Bustos considera que la utilización de uno $u$ otro modo establece una diferencia esencial respecto a la actitud del hablante hacia la verdad o no de las oraciones en que aparecen esos modos. Así, el indicativo compromete en algún sentido al emisor con la creencia de la verdad del complemento, mientras que, con el subjuntivo, el hablante se muestra neutral respecto a ese valor de verdad. Esa diferencia presuposicional se manifiesta únicamente cuando es admisible la alternancia entre los dos modos ya que, si sólo es posible el subjuntivo, no se da la presuposición de neutralidad e incluso se presupone afirmativamente.

Hay otro caso --señalado por Ma L. Rivero-- en que esa diferencia de presuposiciones no se mantiene, como lo demuestran los ejemplos Sentí que venía y Siento que viniera donde el verbo principal es utilizado respectivamente con el significado de "notar" y "dar pena, lamentar". En los dos casos "se presupone la verdad del complemento, 10 que quiere decir que no hay una manera automática de identificar al subjuntivo con la falta de suposiciones sobre la verdad del complemento, y al indicativo con presuposiciones positivas" ("El modo y la presuposición", Estudios de gramática generativa del español, Madrid, Cátedra, 1977, p. 57 ).

Sin embargo, Io anterior no impide que, en general, la utilización de uno u otro modo sea un mecanismo con el que cuenta el oyente para inferir las creencias del hablante respecto a la verdad de 10 que enuncia. Cuando éste emplea el indicativo introduce un nuevo elemento en el contexto, 10 cual contribuye al aumento de 1 a consistencia del mismo. El uso del subjuntivo, en cambio, lo deja inalterado.

La segunda parte del capitulo estudia el empleo de 10 dos modos 
anteriores en las oraciones condicionales. También en este caso, las posibles formas en que se presente el antecedente se corresponden con la expresión de diversas actitudes epistémicas por parte del hablante, que van desde la extrema seguridad en el valor de verdad de la cláusula condicional antecedente a la certeza de su falsedad.

Este es, a grandes rasgos, el contenido de la obra de Bustos. Considero que la mayor dificultad de su lectura radica esencialmente en la falta de una definición clara y sistemática de los conceptos básicos que en ella se utilizan: presuposición, implicación, implicatura... La complejidad aumenta desde el momento en que el autor distingue entre implicación lógica, semántica y léxica, implicaturas conversacionales generalizadas y particulares...etc. Todo ello hace que el lector se pierda en una maraña terminológica de la que no sabe bien cómo salir. Además --como H. Haverkate señala en la reseña que antes cité-- a veces, parecen utilizarse indistintamente términos que antes se han diferenciado. Es lo que sucede cuando al analizar el ejemplo de la página 235 - - Si Juan Pedro hubiera aprobado, no tendría que volver a examinarse--, Bustos afirma que "Hay dos interpretaciones de esta oración, la primera de las cuales presupone o implica que Juan Pedro no ha aprobado" (el subrayado es mío), donde la distinción entre implicación y presuposición parece desaparecer.

Mis últimas reflexiones se refieren a la presentación material de la obra. Ouizá hubiera sido deseable un indice de materias, siempre útil cuando se desea localizar con rapidez un tema concreto. También es necesario indicar que en el aspecto tipográfico hay múltiples errores que, en ocasiones, llegan a impedir la correcta comprensión. Es el caso de las páginas 166 y 167, donde las erratas en la puntuación rompen la estructura sintáctica de las frases.

Por otro lado, la bibliografía es selecta aunque se echan de menos algunos nombres: V. Camps (Pragmática del lenguaje y filosofía analitica, Barcelona, Península,1976), J.Moeschler (Dire et contredire. pragmatique de la négation et acte de réfutation dans 1 a conversation, Berne, Editions Peter Lang, 1982), J. Verschueren(Prag matics. An annotated bibliography, Amsterdam, John Benjamins, 1978), F. Hernández Paricio (Aspectos de la negación, Colección contuxtos, 3, Universidad de León, 1985)... No obstante, la ausencia de este último es comprensible dada la fecha de publicación de su obra.

En conjunto, la obra es una excelente aportación a los estudios de pragmática. Su mérito esencial radica en aplicar los conceptos generales de dicha disciplina al análisis de fenómenos concretos del español. A 10 largo de todo el ensayo, el autor muestra la necesidad de estudiar el sistema de la lengua teniendo en cuenta el uso efectivo de la misma por parte de los hablantes, ya que, si es un principio por todos aceptado que "la lengua es un sistema de signos", no es menos cierto que éstos adquieren todo su significado y "se constituyen como tales en el proceso de su utilización" (p. 11). Hay que considerar, 
por 10 tanto, todos aquellos factores que de un modo u otro contribuyen a la adecuada y feliz realización de los intercambios comunicativos.

R. MORANT I E. SERRA, Els modificadors intraoracionals i interoracionals, Universitat de valència: Biblioteca lingiística catalana, 1987, pp. 109

La gramática liminar tiene por objeto como el propio Angel López García afirma la explicación y predicción de "descripciones metalinguísticas relativas a regularidades constatables en el lenguaje natural" (Estudios de lingiística española, Barcelona: Anasrama, 1983, p. 30).

Dentro de esta nueva teoría del lenguaje, se incluye esta obra que hoy llega a manos de los lectores. Sin embargo, lo anterior no debe hacernos caer en el temor a lo críptico y complejo, pues como en la Nota preliminar se declara, la obra pretende conseguir un nivel científico que no esté reñido con la sencillez y claridad; cualidades estas que, hoy dia, muchos autores evitan buscando, afanosos, "sofisticadas" teorías cientificas que sólo ellos entienden.

La obra se estructura en dos partes claramente diferenciadas -cada una de un autor-- que se corresponden con 10 anunciado en el título. En la primera se estudian los modificadores intraoracionales y en ella R. Morant analiza el adverbio y la negación a través de una serie de epigrafes que favorecen un acercamiento sistemático y exhaustivo al tema.

En 1o que se refiere a la primera de las cuestiones --el adverbio-- se señalan las dificultades que plantea su estudio y que vienen dadas por los numerosos términos que allí se incluyen, la gran diferencia formal entre las palabras agrupadas alrededor de esta categoría y la diversidad funcional de ésta. Nos extraña que en relación directa con esta problemática no se mencionen las soluciones propuestas por Alarcos en el capitulo "Aditamento, adverbio y cuestiones conexas" incluido en Estudios de gramática funcional del español, Madrid: Gredos, 1980, pp. 307-341; obra que, sin embargo, es citada en la bibliografía. En este sentido, también serían fundamentales las conclusiones de $H$. Martinez Garcia (El suplemento en español, Madrid: Gredos, 1986) en torno a este tema; aunque en este caso, la ausencia parece justificada clebido a la fecha de publicación de ambas obras.

Tras un análisis de las categorias relacionadas con el adverbio, 
el autor se centra en la definición de éste. Expone, en primer lugar, la postura de Jespersen formulada en su obra La filosofía de la gramá tica, Barcelona: Anagrama, 1975. Este, de acuerdo con su clasificación de las palabras en primarias --el sustantivo--, secundarias --el adjetivo y el verbo-- y terciarias --el adverbio--, define este último como aquel término que determina otras palabras pero no puede ser determinado por nadie.

Para R. Morant el adverbio se caracteriza porque "incideix sobre la relació establerta entre un predicat i quasevol dels seus arguments. No sempre és optatiu i de la seua collocació en la frase depén, de vegades, el seu valor" (p. 42).

En lo que se refiere a la clasificación y tras mencionar los criterios que otros han utilizado, el autor diferencia tres grupos: 1. Locuciones adverbiales; 2. Adverbios breves y 3. Adverbios en -mente. Un estudio de los mismos le lleva a distinguir en los dos últimos varios subgrupos. Llama la atención que R. Morant deje fuera de tal categoria términos tradicionalmente en ella incluidos como las partículas de afirmación, negación y duda asi y los 11 amados adverbios de lugar y tiempo a los que él considera deícticos.

Dos conclusiones, que recogen la definición y clasificación propuestas por el autor, cierran el primer capítulo de esta parte.

El tema de la negación se inicia haciendo referencia a su estudio en ciencias no lingiísticas. La negación, que es en palabras de Hernández Paricio "uno de los universales más seguros" (Aspectos de la negación, Universidad de León: Colección Contextos, 3, 1985, p. 9), es unalizada desde distintos campos: la lógica, la filosofía y la psicología entre otros. Es evidente, por tanto, que dicha cuestión constituye un cruce básico de diversas disciplinas. No obstante, en cada ciencia, el funcionamiento y los caracteres del sistema negativo son autónomos y se rigen por leyes propias. Esto explica que, a continuación, R. Morant se centre en la negación linguistica estudiándola desde el punto de vista de la fonética, la morfología, la sintaxis, la psicomecánica... etc.

Desde la perspectiva fonética, son fundamentales las consideraciones que hace Jespersen en la obra ya antes mencionada, .... cuales la historia del proceso negativo consiste en un movimiento oscilatorio entre el debilitamiento $y$ el refuerzo de la negacion.

Por su parte, la negación morfológica atiende a la formación de palabras mediante prefijos negativos. Hay que diferenciar los antónimos léxicos (hombre-mujer) y los antónimos morfológicos o gramaticales (normal-anormal). En este tipo de negación no faltan los problemas. Por ejemplo, hay palabras con prefijo que no se oponen a ninguna base. Es el caso de imbécil/*bécil o imberbe/*berbe. otras veces, por el paso del tiempo, se deja de reconocer el antiguo prefijo 
negativo. Es 10 que ocurre en infante.

Echamos en falta la mención de las valiosas aportaciones que Mercedes Brea (Antónimos latinos y españoles. Estudio del prefijo IN-, Santiago de Compostela, 1980) ha hecho en el campo de la negación morfológica. En concreto, dicha autora explica los tres términos antes citados y refiriéndose al último afirma que "ha sufrido un proceso de lexicalización similar al de INIMICUS, aunque más complejo" (p. 31).

La negación, desde el punto de vista semántico, se refiere sobre todo a la antonimia. Se distinguen cuatro casos: los contrarios (grande/pequeño), los contradictorios (casado/soltero), los correlativos (hombre/mujer) y. los reciprocos (comprar/vender).

Atendiendo a la descripción pragmática, el autor incluye las opiniones de Searle y Ducrot. El primero, teniendo en cuenta la fuerza ilocucionaria, es decir, la actitud que manifiesta el hablante frente al contenido de lo que dice, distingue entre negación ilocucionaria y negación proposicional. El segundo, por su parte, habla de negación descriptiva y negación metalinguística.

E1 punto clave de este recorrido a lo largo de los estudios sobre 1a negación 10 constituyen las opiniones de Jespersen que se resumen en cuatro puntos esenciales: 1. La negación linguística convierte un término en su contradictorio; 2. Establece un tripartición distinguiendo entre lo positivo, 10 incierto, y lo negativo; 3. Analiza el tema de la negación y los cuantificadores; 4. Diferencia dos tipos de negación, especial y nexal, según afecte a una sola idea o a la combinación de las dos partes del nexo.

Las ideas de la psicomecánica respecto a la negación se exponen tomando como representante a Guillaume. Desde esta perspectiva, la negación es concebida como un movimiento que va a la inexistencia, hacia 1 a ausencia.

Para terminar este repaso a las diversas teorias que sobre la negación se han formulado, se alude a Tesnière que, asumiendo la distinción formulada por Jespersen, diferencia entre negación nuclear y negación conexional.

Este análisis crítico de la negación en las diferentes escrelas sirve para que el lector conozca el tratamiento básico que recibe el tema desde las diversas perspectivas de estudio. De este modo, aunque no sea especialista en la materia, consigue alcanzar una vision de conjunto, imprescindible, antes de introducirse en el estudio especifico del funcionamiento de la negación en catalán.

No obstante, existen algunas lagunas, pues no se mencionan ciertas obras esenciales. Un ejemplo es la de Hernández Paricio que, al lado de un exhaustivo repaso de los estudios anteriores, desarrolla una completa teoria sobre la relación entre negación y cuantificación 
por un lado, y negación y modalidad por otro, llegando a "la consideración de la negación como relación integrada dentro de un sistema gradativo o escalar, de fuerza variable que cuantifica relaciones llegando a su disolución o simplemente atenuándolas, dependiendo siempre de la propia naturaleza de lo cuantificado" (Aspectos de la negación, p. 218).

Sobre el catalán hay que decir que éste ocupa un lugar intermedio en el conjunto de las lenguas románicas en lo que respecta al desarrollo del sistema negativo. Comparte características con el francés y el español y a la vez tiene rasgos peculiares y especificos.

El capítulo se cierra con el análisis de tres elementos --ne, tampoc, pas-- y unas conclusiones que reiteran la universalidad de un tema que es estudiado desde las más diversas disciplinas.

La segunda parte de la obra se dedica al estudio de los modificadores interoracionales, es decir, las conjunciones. Para su desarrollo, el autor, E. N. Serra, ha seguido muy directamente los postulados establecidos por Angel López García en el capitulo "Las conjunciones y la oración compuesta", incluido en su obra Estudios de linguística española, Barcelona, Anagrama, 1983, pp. 43-65.

Partiendo de considerar la conjunción como la categoría que enlaza oraciones o bien miembros o elementos de una misma oración, se distinguen dos clases fundamentales: las de coordinación y las de subordinación en las que a su vez se diferencian varios subgrupos.

Las primeras enlazan dos oraciones independientes vinculadas por su sentido constituyendo 1 a oración compuesta o bien unen distintos elementos de un sujeto, un complemento, ... etc. En este sentido, habría que hablar de coordinación oracional y coordinación sintagmática, distinción que, sin embargo, no es mantenida ni por las gramáticas tradicionales castellanas, ni por los primeros modelos de gramática generativa.

Por su parte, las conjunciones de subordinación introducen las oraciones subordinadas incluyéndolas en las oraciones totales.

Establecido el punto de partida, E. N. Serra formula las tres cuestiones que van a constituir el objeto de su estudio: 1. Las conjunciones causales aparecen entre las coordinantes y las subordinantes ¿qué diferencia hay entre ellas? 2. Definida la conjunción comno elemento de enlace, analiza su posible conflicto con otros elementos que cumplen la misma función, por ejemplo las preposiciones; 3. El supuesto significado de las conjunciones.

Sobre el primer punto y tras señalar la falta de acuerdo existente, E. N. Serra concluye que "les conjuncions causals (...) denoten que entre les oracions que enllacen hi ha un tipus de relació que no és ni de coordinació ni de subordinació" (p. 83), en la misma 
línea que autores anteriores, como Rojo, Blesa o Vera Luján, los cuales defienden la existencia de una relación de interdependencia entre la causa y el efecto.

Sobre la interferencia entre las funciones prepositiva y conjuntiva, el autor explica que se debe a que ambos comparten el papel de relacionantes en una misma oración. La diferencia que se puede establecer es la siguiente: "la conjunció coordina elements sintactics equivalents i la preposició subordina un terme a un element anterior" (p. 84).

Por otro lado, desde el punto de vista histórico, las conjunciones proceden de otras categorías gramaticales con las que todavía tienen una cierta relación. Son las preposiciones y los adverbios relativos, relacionados en uno y otro caso con la partícula originariamente relativa que, lo cuaj también las vincula con la clase de los relativos.

Desaparecidas la mayor parte de las conjunciones latinas, cuando en la Edad Media se tenga necesidad de ellas, se crearán a partir de locuciones prepositivas, relativas y adverbiales.

A. M. Badia establece tres etapas en el desarrollo de los cuadros conjuntivos catalanes que van desde la simple yuxtaposición, pasando por el empleo de un elemento de relación que conserva su sentido especifico, hasta llegar a la pérdida de dicho valor y a la fosilización de esos elementos como conjunciones (Gramática catalana, 20 Vol., Madrid, Gredos, 1962)

De las relaciones conjunción-preposición-adverbio/relativo no se deduce la equiparación de esas tres categorías, pues si resulta dudosa la conveniencia de diferenciar conjunciones y relativos/adverbios por un lado y conjunciones y preposiciones por otro, es evidente que los relativos y las preposiciones no tienen casi nada en común.

Sobre el tercer punto--el significado de las conjuncioncs-- hay que decir que, si de acuerdo con su naturaleza y función aquéllas se dividen en coordinantes y subordinantes y se clasifican en copulativas, disyuntivas, adversativas ... etc. ello hace pensar que sí 10 poseen. Sin embargo, hay que tener en cuenta que todas las relaciones coordinadas o subordinadas pueden reducirse a la simple yuxtaposición, de modo que la conjunción "es limitaria a confirmar el tipus de relació que es pot obtenir mitjançant la simple juxtaposició d'oracions" (p. 90) careciendo, por tanto, de significado propio. Por otro lado, las conjunciones coordinativas pueden desempeñar las funciones de las subordinantes, pero no al contrario.

Fstablecida esta contradicción, hay más argumentos a favor de que tales clementos carecen de significación, a pesar de que si tienen un cierto sentido. 
A continuación, se desarrolla el problema del estatuto gramatical de la conjunción, revisando las diversas opiniones que sobre el tema se han formulado, desde su consideración como simple particula señaladora de relaciones estructurales hasta la teoría de Coseriu sobre el estatuto significativo y funcional de las tres conjunciones latinas de coordinación copulativa --et, ac, -que-- de las que sólo ha pervivido el término no marcado et.

Otra postura tiende a considerar las conjunciones como elementos performativos, es decir, como expresiones superficiales de la actitud del hablante.

La conclusión final de E. N. Serra establece que la conjunción constituye una categoría morfológica, lo que acarrea dos importantes consecuencias ya señaladas por Coseriu. Por un lado, las distintas conjunciones se agrupan en paradigmas cerrados, y por otro, su establecimiento se fundamenta en entornos sintagmáticos, es decir, entornos de concordancia.

Ya para terminar, el autor resume el mecanismo liminar de la categoría conjunción desarrollado por Angel López García en el capítu10 antes citado. Desde esta perspectiva, la conjunción se sitúa en el componente morfológico como categoría relativa a los realces que se producen en la estructura tópico/comentario. La aparición de un tipo u otro de conjunción determina las diversas posibilidades de realce.

Consideramos que esta obra cumple con el objetivo que se propone de ser una introducción a los temas en ella analizados. Si bien no se alcanza una gran profundidad en las cuestiones propuestas, si se exponen las ideas básicas y esenciales con una gran claridad que, sin embargo, podría haber sido mayor en la segunda parte si, al igual que ocurre en la primera, se hubiera utilizado la división en epigrafes que facilitan la lectura y permiten una mejor comprensión.

RICARDO SENABRE, Literatura y público, Madrid: Paraninfo, 1987, pp. 126.

Los que, por dedicación profesional, andamos metidos en la practica, estudio y enseñanza de la critica literaria tenemos una experiencia un tanto desorientada respecto a la bibliografía que sin cesar va apareciendo en y sobre nuestro campo. por un lado, abundan escritos - no breves, en general, ni de fácil lectura-- que descle miradores diferentes y con diferentes enfoques, se asoman teóricamente al problema insondable de la titeratura y contemplan las cuestiones que desde siempre este problema ha venido suscitando: el texto, los 
géneros 1 iterarios, las preceptivas, los métodos de análisis, etc. ... etc. Por otro, abundan, aunque no tanto, escritos en los que, supuesta, previa y gratuitamente, la solución teórica del problema, los textos, considerados de entrada como literarios, son tomados como objetos sometidos a análisis y comentarios tan diversos como diversos son los autores de esos libros, invariablemente con el fin de demostrar algo que se admite ya como demostrado.

Causa, por ello, sorpresa la aparición de un libro en el que el autor, sin rizar el rizo de la teoría sobre la teoría, ni dar recetas de salutífero bálsamo crítico-lector válido a todo evento, ofrece un producto que calla más de lo que dice --con ser tanto lo que dice-- y no adormece la iniciativa del estudioso lector; todo lo contrario: a su olorcillo apetitoso queda estimulada la iniciativa personal de estudio y se abren las ganas de leer, porque el conjunto --la materia o contenidos-- es presentado de una manera amena, eficazmente pedagógica y plena de atractivo. La sorpresa, pues, se va tornando en maravilla página tras página, y uno se encuentra inesperadamente sumido en el goce de un simposio magistralmente -qque no magisterialmente-preparado y servido por la madurez sazonada de un experto --de un maestro-- que sabe muy bien lo que ofrece, y sabe ofrecerlo.

Como es lógico, el título del libro es el primer aviso indicativo y significativo. Pero sólo terminada la lectura, uno se percata de que el título ha sido (es) un simple aunque activisimo acicate, un aperitivo para que el estudioso lector quede enganchado y vaya degustando con placer reconfortante la completisima variedad de esquisitos manjares --no todos dulces, algunos presentados con su deje de crudeza-- que no se imaginó que pudieran anunciarse tras las llamativas letras en rojo que arden como brasas en la blancura tersa de una discreta portada.

E1 lector --y el lector en este caso soy yo-- piensa, en principio, una de estas dos cosas: o que se las va a haber con un tratado sobre las relaciones de la letra impresa con el gran público a través de la red barredera del mercado editorial, o que va a poder regodearse con una exposición de bolsillo de la, hoy en boga, teoria de la recepción, de ascendencia germana. Pero, por suerte para él, el lector se equivoca.

Verdad es que se explicita el problema de la imposibilidad del escritor --del español sobre todo-- para vivir de 10 que escribe, salvo contadisimas excepciones; verdad es que hay un discretisimo y comprensivo borrón sobre la línea divisoria entre literatura y subliteraturas; verdad es que se alude al panorama lector y cultural. Pero en nigún momento se hace mención de la teoría de la negatividad de Adorno, por ejemplo: se le asigna el guiño referencial de cita implícita, para iniciados.

Verdad es que, arrancado del esquema ya académicamente clásico de la comunicación, el autor se centra fijamente en el receptor--1ector, 
público en general-- y lo constituye en idea directriz y axial de todo el libro. Pero en nigún momento se hace referencia a la dicha teoría estética de la recepción: a uno solo de sus padres --Jauss, Rothe, Iser ...- ni a su abuelo Gadamer, a ninguno. Sin embargo, se afirma el hecho de que una obra artística puede ser como es porque su autor, deliberada o inconscientemente, ha tendido en cuenta el carácter, los gustos o las apetencias de sus posibles receptores. Como se ve, nuevo guiño para los enterados, y para los que quieran enterarse.

Verdad es que, en consecuencia, es admitida la responsabilidad de la realidad social --del contexto social-- en el nacimiento de la obra, y en el modo peculiar de ese nacimiento, y el libro la subraya. Pero no se mostraba a Goldmann ni se habla de estructuralismo genético; ¿es que no hace falta?

Y así sucesivamente.

Esto botones de muestra --muestra exigua, como corresponde al talante de estas líneas mías-- me inducen a pensar, me fuerzan a hacerlo, que tengo ante mis ojos un modélico "libro de texto". Los profesores universitarios abominamos cerradamente --y con qué solemidad no raras veces-- de los sagrados y consagrados "apuntes", pero sabemos que es una abominación inútil. El profesor Senabre ha encontrado, a mi modo de ver, una productiva solución a esta secular paradoja escolax. Este libro contiene las ideas fundamentales --reducibles a notas o apuntes-- de la disciplina llamada Crítica Literaria --o Teoria de la Literatura--, pero el autor las ha enriquecido con una abundantisima bibliografía contextual, no siempre explícita, que el alumno debe de conocer ya --o consultar para conocerla-- y que abarca, a 10 largo y a 10 ancho, el periodo entero de la Historia de la Literatura en el que, inteligentemente, han sido borradas las artificiales líneas de periodización que hacian de ella un tren de contenedores estancos. Pero no sólo de la Literatura española; también de las literaturas clásicas, románicas y anglosajonas. Con este dato, tan simple y en apariencia exclusivamente erudito, Literatura y público se convierte, sin más, en un tratado de Literatura compitrada, con multitud de ejemplos. Dato que se confirma por el hecho de que los títulos de las obras se ofrecen en su lengua original, lo mismo que las citas textuales o críticas --inglés, alemán, francés, italiano--, con 10 que se supone un lector-estudioso --alumno-- suficientemente pertrechado en el conocimiento y manejo de esas lenguas; y si no 10 está, que se pertreche. En fin, se trata de un "libro texto" ejemplar, pero que precisa un profesor, también ejemplar, que desborde el libro mismo desenmascarando alusiones, iluminando zonas deliberadamente dejadas en penumbra, subrayando y sombreando esbozos, coloreando blancos y regros, es decir, un profesor que trabaje y haga trabajar sobre "el banco de pruebas de la clase".

De este modo, el libro y la clase quedan convertidos en una 
exposición clara y suficientemente sistemática del estado actual de cuestiones tan interesantes, importantes, candentes y básicas como éstas: dificultad de una definición unívoca de Literatura; criterios para intentar captar cuándo y por qué un texto es literaris o no; reconocimiento inconcluso de que la Literatura es un acto de comunicación; importancia del receptor cualificado o destinatario activo, que condiciona la forma del mensaje; maneras concretas de condicionarlo; importancia del paso del Tiempo, que influye sobre el éxito o fracaso --momentáneo o no-- de una obra, porque el Tiempo mismo contempla diacrónicamente al destinatario y lo va configurando; la lectura como medio de acceso al texto; la lectura previa, la lectura restringida, la recitatio como modos prácticos de sondeos que el escritor emplea antes de dar al 'gran público' su obra; la tarea del público cooperador; el problema de la traducción y de las modas narrativas; la historia de la literatura; la teoría de la comunicación; la oralidad y la escritura; el oficio de escibir; el placer del texto; la poesía y la prosa; el teatro; la biografía como coartada y la censura; la epopeya, la historia y la novela... Pero, ¿qué temas faltan aqui para que este libro pueda ser un cumplido desarrollo de un programa básico de Crítica Literaria? Ninguno.

Insisto en que todo se expone con la madurez del buen sentido, con la prudencia sin radicalismos que un magisterio en activo enseña y propicia, y con el recurso al elemental truco pedagógico que sólo los maestros de verdad dominan, a saber, el de explicar "la materia" partiendo de cualquier punto importante de ella: aquí el punto central se llama "público". En una palabra: el alumno está permanentemente en el punto de mira de la reflexión del dato erudito pertinente, de la anécdota amable..., un alumno que es respetado siempre, pero que --o precisamente porque-- queda informado en extensión, en profundidad, de manera critico-racional y nunca forzado en su libertad. Todo profesor sabe que, auque parezca mentira, su primer objetivo se cifra en lograr que el alumno no odie la asignatura. :Aquí se consigue que la ame! Con lo que, curiosamente, la tesis central del libro se demuestra válida. El alumno-1ector se convence de "poder" ser su propio profesor.

¿Libro del alumno, pues? Si. Pero también "libro del profesor". Para los profesores lo ha hecho, aunque sin decirlo, y, tal vez, sin pretenderlo, un colega que sabe mucho pero que nunca dice que sabe, y 1o ha hecho con esa dificil facilidad que es conquista callada de estudio y experiencia.

En conclusión. Yo he realizado mi lectura de este libro. Y la he apuntado a vuelapluma con unas impresiones personales. A ellas puede ser debida la apariencia un tanto heterodoxa de esta reseña. También esto tien su explicación: a ejemplo del maestro no quisiera que mi lectura influyera en otras lecturas. Pero no me ruborizo al escribir que si quisiera que las provocara. 
With the proposal of a new theory about linguistic sign, we think we are also proposing a new metalinguistic theory of human languages. Because our sign conception is topologico-dynamic, nonsymmetrical and with capacity to integrate previous conceptions, thus language is dynamic like Generative Grammars or the new mathematical theories about it; it is also asymmetrical like Liminar Grammars - rather, its asymmetry is two-faced, because we put, in the same equal izing level, Semantics and Syntax- and it is finally integrative of Stoic sign, Peircean sign, structural sign, etc. as Perceptual and Cognitive Grammars are, at the same time, integrative of old linguistic schools.

After that, this new signic proposal can deductively hypothethize the nature and number of the linguistic sciences, what are the boundaries among them and why the relation between each part of the sign can justify well-known criteria of 'necessity' 'arbitrariness' and 'motivation' in the analysis.

Lastly, perceptual dynamismus lets us maintain that each linguistic science exercises as metalanguage to make explicit the other object-linguistic sciences, acting from nucleus to periphery, and viceversa, always in a two-faced vectorial reading of the World/Language relation. With this, the integrative system leads us even to Phonical and Lexical Pragmatics, not only to Semantics-and-Syntax binomial.

\section{EN TORNO A LA DEFINICION LEXICOGRAFICA}

From all the texl that form the article of a dictionary, it corresponds to the lexicographical definition itself all that remains once we remove all the cronological, dialectal, social or expressive indications that the dictionary manes about the word we are considering.

To study the formal aspects of a lexicographical definition it is important to understand the technological, and not scientific, nature of the dictionary.

on the other hand, we must consider that the dictionaries are works which need continuous reviews. because it is difficult to organize thousands of autonomous cells without making mistakes and because the described object modifies itself very quickly. If the articles were related among themselves too close, any of the small 
modifications made on the dictionary would lead us to a general modification of $i t$, and that would be negative. An important source of misunderstandings and problems for a lexicographer is the metalanguage in which the definitions are expressed. Another apparently unsolvable problem that lexicographer find is the one about circular definitions.

\section{CONDITIONAL OR RELATIVE PROBABILITY}

We sketch the calculus of probability as a mathematical abstract theory. In doing so, we follow kolmogoroff's approach. Also we deal with Renyi's approach. We prove that Renyi's approach is richer than Kolmogoroff's.

Since probability is an abstract mathematical theory devoid of any specific factual content, we can interpret it in some different ways: propensity, randomness and statistical.

Following Bohr we take it that quantum mechanics deals with relations, where probabilities refer to the potentiality that exists in some given conditions before any interaction takes place.

\section{LA FORMACION DEL FENOMENO REPRESENTACIONAL:}

\section{CONSTRUCCION Y COGNICION}

This paper studies the meaning of the concept of representation and the origin of such process, showing the strict relation linking its emergence with the evolution of the process of self-reproduction. Moreover, herein is examined the role played by reproduction in the very constitution of representation. Thus is reached a first characterization of representation constructive functionality. Relying on this idea of functionality we abord in the last step the analysis of the relation between representation and cognition, wherein the so called problem of adequacy is posed.

\section{EL CASO DEL REALISMO INTERNO DE HILARY PUTNAM:}

TRANSCENDENTALISMO Y DESARROLLO TEORTCO

In this paper we analyse the Internal Realism of Hilary Putnan as erected from a transcendental idealism/empirical realism distinction type. We succesively study his philosophy of language, his epistemology and his theory of rationality and action. We try to show the inadecuation of that frame and how the untheorizabilits generated for the epistemic can be eliminated developing new 


\section{LA POSTURA INIENCIONAL}

Intentionality is a classical topic in the philosophy of mind. In this article the author deals with Dennett's recent analysis of the concept and puts into context the main points of Dennett's view on the subject. Intentionality has been frequently understood as "deep" and essential property of beings such as persons, but not of artifacts endowed with the so called artificial intelligence. Dennett's endeavor to shift the analysis of intentionality from this romantic outlook to one wherein successful attribution of intentionality is the problem to be solved is developed through the scrutiny of subjects such as reason and evolution, belief and interpretation, causal transmission and mental content, realism and objectivity, etc.

Dennett's stance regarding intentionality turns out to be an open one. Intentional attribution should be assessed on the grounds of its explanatory utility as a strategy that enables us, -at least up to a certain degree- to predict the conduct of "intentional" agents. The author ends up by asking some relevant questions that pose some of the pending problems about the topic of intentionality.

\section{¿QUE FILOSOFIA? EL DEBATE ENTRE HABERMAS Y RORTY}

When it looked as if the several ways of doing philosophy had nothing in common, the dialogue between Habermas and Rorty emerged steadily few years ago. Both of them, being outstanding representatives of their own traditions, were conscious of their failures; both of them argue for original views about the nature and history of philosophy; both of them resort, in their respective proposals, to ideas clearly from the other tradition Habermas to pragmatism, Rorty to hermeneutics-. Too many coincidences to ignore them.

This paper contends that their dissent arises from what they share. We will consider their assessment of the philosophical task, the reasons that have contributed to the development of their respective conceptions - the Conversation of Mankind, the Theory of Communicative Action and what is really at stake in the debate: the historicity or not of the intersubjective character of rationality. 

ALEZA IZQUIERDO, M.: Ser con participio de perfecto en construcciones activas no oblicuas (español medieval), Anejo de III de Cuadernos de Fiolologia, Universidad de Valencia, 1987; pp. 119.

ALVAREZ BORGE, I.: El feudalismo castellano y el libro Becerro de las Behetrías: La Merindad de Burgos, Biblioteca de Castilla León, Junta de Castilla y León y Universidad de León, 1987, pp. 196.

AMOROS, C.: Sören Kierkegaard o la subjetividad del caballero, Editorial Anthropos, Barcelona, 1987, pp. 264.

ECHENIOUU ELIZONDO, Mạ T.: Historia lingüistica vasco-románica, Colección Filología, Editorial Paraninfo, Madrid, 1987, pp. 144.

FINE, A: The Shaky Game. Einstein Realism and the Quantum Theory, The University of Chicago Press, Chicago and London, 1986, pp. xi + 186.

GARCIA MORENTE, M.: Escritos desconocidos e inéditos, Prólogo por Antonio Millán-Puelles, B.A.C., Madrid, 1987, pp. xvi + 489.

GONZALEZ, G.: Dialéctica escolástica y lógica humanística. De la Edad Media al Renacimiento, Ediciones Universidad de Salamanca, Salamanca, $1987, \mathrm{pp} .441$.

GROENENDTJK, J.; JONGH, D. de; STOKHOF, M. (Eds.): Foundations of pragmatics and Lexical Semantics, Foris Publications, Dordrecht, 1986, pp. VIII + 156.

GROENENDIJK, J.; JONGH, D. de; STOKHOF, M. (Eds.): Studies in Discourse, Representation Theory and the Theory of Generalized Quantifiers, Foris Publications, Dordrecht, 1986, pp. VIII +215.

MALLO, F.; MURES, Ma J.; HUERGA, C .: Decisión empresarial, Universidad de León, León, 1987, pp. 352.

ORTIZ-OSES, A.: Mitologia cultural y memorias antropológicas, Editorial Anthropos, Barcelona, 1987, pp. 489. 
PEÑA, L.: Fundamentos de ontologia dialéctica, Siglo Veintiuno de España Editores, Madrid, 1987, pp. 422.

PTOLOMEO, Las hipótesis de los planetas, Introducción y notas de Eulalia Pérez Sedeño, Alianza Editorial, Madrid, 1987, pp. 123.

REGUERA RODRIGUEZ, A. T.: La ciudad de León en el Siglo XIX, Colegio oficial de Arquitectos de León, León, 1987, pp. 172

REGUERA RODRIGUEZ, A. T.: La ciudad de León en el Sig10 XX, Colegio Oficial de Arquitectos de León, León, 1987, pp. 209.

RODRIGUEZ CAMARERO, L.: Ia potencia del entendimiento y de la imaginación en Spinoza, Universidad de Santiago de Compostela, Santiago de Compostela, 1986, pp. 112.

SECo, M.: Estudios de Lexicografía Española, Colección Filología, Editorial Paraninfo, Madrid, 1987, pp. 258.

VERMAL, J. L.: La critica de la Metafisica en Nietzsche, Prólogo de Eugenio Trias, Editorial Anthropos, Barcelona, 1987, pp. 235.

WISDOM, J. 0.: Philosophy of the Social Sciencies II: Schemata, Gower Publishing Company, Brookfield, 1987, pp. xi +210. 
ALCOBA, S.: Significado y puntuación: España y Ia OTAN

$\mathrm{V} / 9,35$

$\mathrm{I} / 1,129$

II $/ 4,139$

III $/ 6,115$

$\mathrm{V} / 9,107$

IT/3, 131

IV $/ 7,63$

II $/ 3,21$

III $/ 6,73$

II $/ 3,7$

II $/ 4,7$

$\mathrm{V} / 9,19$

$\mathrm{IV} / 7,55$

$\mathrm{IV} / 8,7$

$\mathrm{IV} / 7,27$

II $/ 4,73$

$V / 10,7$

II $/ 3,53$

III $/ 6,7$

$\mathrm{I} / 2,105$

I/ 1, 21

$v / 9,69$

V/10,117 
GONZALEZ GONZALEZ, Ma J.: El espacio urbano y

su contenido social

GUTIERREZ ORDONEEZ, S.: La determinación inmanente de las funciones en sintaxis

GUTIERREZ ORDOÑEZ, S.: Sobre las categorías, las clases y la transposición

GUTIERREZ ORDOÑEZ, S. E IGLESTAS BANGO, M.: Sobre el principio de articulación en linguística

GUTIERREZ ORDOÑEZ, S.; IGLESIAS BANGO, M. y RODRIGUEZ DIEZ, B.: Más sobre el sujeto icon? preposición

IGLESIAS BANGO, M.: E1 artículo en español: aportaciones a un viejo debate

IGLESIAS BANGO, M. y GUTTERREZ ORDOÑEZ, S.: Sobre el principio de articulación en lingüistica

IGLESIAS BANGO, M., RODRIGUEZ DIEZ, B. y GUTTERREZ ORDOÑEZ, S.: Más sobre el sujeto ¿con? preposición

LAFUENTE, Ma I.: Unidad y rupturas de la razón

LAFUENTE, Mą I.: Progreso y contratiempo: la reconstrucción hegeliana de 1 a Historia de la Filosofía

LAFUENTE, Ma I.: La idea de vida en Dilthey y Ortega

LAMBERT, J.: Un modèle descriptif pour l'étude de la littérature. La littérature comme polysystème

LIZ, M.: El caso del realismo interno de Hilary Putnam: trascendentalismo y desarrollo teórico

MARTINEZ, J.A.: Para (re)leer a Hjelmslev

MONTERO MOLINER, F.: Lenguaje y experiencia en 1 a fenomenología de Husser

MONTERO MOLINER, F. La semántica de la subjetividad

MONTESINOS, J.J.: Fractal y dimensión

MORALA RODRIGUEZ, J.R.: E1 nombre propio jobjeto de estudio interdisciplinar?

$V / 9,127$

$I / 2,41$

III $/ 5,75$

$I I / 3,67$

II $/ 4,87$

IV $/ 7,103$

$I I / 3,67$

$I I / 4,87$

I/ 1,59

I/2, 83

III $/ 5,25$

$V / 9,47$

$\mathrm{V} / 10 ; 87$

$\mathrm{I} / 1,39$

I $/ 2,7$

$\mathrm{TV} / 7,7$

III $/ 6,163$

$\mathrm{IV} / 8,49$

$V / 10,71$

$\operatorname{III} / 5,65$

IV $/ 8,63$

II $/ 3,81$

II $/ 4,49$

IV $/ 8,21$

I/2, 57

III $/ 5,7$ 
PEREZ DE LA VEGA, M.: El origen de la genética

PEREZ SEDEÑO, E.: Las observaciones de Hiparco

PEREZ TORAL, M.: Usos impersonales del verbo "hacer"

REGUERA RODRIGUEZ, A.T.: Instrumentos conceptuales para la elaboración de un teoría demográfica basada en el materialismo histórico

II $/ 3,175$

IV/7, 43

$\operatorname{III} / 6,29$

$I / 1,93$

II $/ 4,87$

IV $/ 8,71$

$\operatorname{III} / 5,113$

$\mathrm{V} / 10,29$

III $/ 5,49$

IV $/ 7,147$

$\mathrm{V} / 10,57$ III/5, 141

I $/ 1,9$

$\mathrm{I} / 2,27$

$V / 9,7$

$\mathrm{II} / 4,27$

III $/ 6,47$

$\mathrm{V} / 10,107$

$I / 2,135$

II/3,227

IV/7, 161

$\mathrm{V} / 10,145$

ALVAREZ, J.R.: Varia gouldiana 
ALVAREZ GOMEZ, A.: De la tradición a la razón

BAHM, A.J.: Organicism: A "More Holistic"

$\mathrm{V} / 10,157$

CARANTOÑA ALVARFZ, F,: Fernand Braudel: In memoriam

CoRTIzo, J.: A propósito del II Coloquio de Geografía Cuantitativa

$I I I / 6,223$

III $/ 6,219$

CHAMOSA GONZALEZ, J.L.: A propósito de una traducción de la obra poética de Joyce

$\operatorname{III} / 5,173$

IV $/ 7,197$ clásico de H. G. Wells: The Time Machine

CHAMOSA GONZALEZ, J.L. \& GUZMAN GONZALEZ, T.: Margaret Oliphant: An Open Door to the Unknown

$\mathrm{V} / 10,161$

$I I / 4,175$ L. Alas y "La Regenta" de J. Rutherford

IV $/ 8,115$

$I / 2,129$

TI/4, 161

III $/ 6,209$

$\mathrm{V} / 10,161$

IV $/ 8,123$

III $/ 6,179$

$\mathrm{IV} / 8,141$

II $/ 4,181$

IV $/ 8,151$

II $/ 4,191$

IV $/ 8,157$

III $/ 6,189$

$V / 9,163$

$\mathrm{V} / 9,155$

REgUERA RODRIGUEz, A.T.: Notas sobre un debate: guerra, estrategias espaciales y

urbanismo en Nicaragua

IV $/ 8,101$ 
SAGUILLO FERNANDEZ-VEGA, J.M.: La relevancia

de un enfoque filosófico de la lógica

IV $/ 7.175$

I/ 1,163

II $/ 3,211$

SANCHEZ, M.E. Evolución y problema religioso

III $/ 5,179$

SANCHEZ, M.E.: La música, "un espacio ausente"

$111 / 5,179$

SOBRINO CERDEIRIÑA, A.: El signo en

arquitectura

III $/ 5,159$

TOME, M.: Georges Perec y J.M.G. Le clézio: la creación literaria ante el sistema socio-ideológico de los objetos de consumo

IV $/ 7,187$

VALCARCEL, A.: Vicios y virtudes de la ética anlítica

$[1 / 3,201$

VIEJA DE LA TORRE, Ma T. de 1a: E. Tugendhat: fundamentación de normas y reglas

$V / 9,147$ 